\title{
CLINICAL EXPERIENCE WITH THE MELROSE OXYGENATOR AT NORMAL AND REDUCED TEMPERATURES
}

BY

\author{
P. G. F. NIXON, V. A. GRIMSHAW, L. A. CATCHPOLE, H. M. SNOW, AND K. LAWRANCE
}

From the University of Leeds, the Department of Thoracic Surgery in the United Leeds Hospitals, and the Department of Thoracic Surgery, the General Infirmary, Leeds

(RECEIVED FOR PUBLICATION MARCH 15,1960 )

A heart-lung machine was used in the surgical treatment of 20 patients with congenital heart disease and one patient with rheumatic mitral incompetence during the latter half of 1959 in the Department of Thoracic Surgery in the General Infirmary at Leeds. One patient died a month after perfusion from staphylococcal septicaemia, and one died from heart block on the third day after operation. Nineteen are alive and well.

The essential parts of the heart-lung machine are an oxygenator, a pump (Nixon, 1959a), a filter and bubble trap, and a heat-exchanger.

Catheters in the superior and inferior caval veins permit blood flowing from the upper and lower parts of the body to be directed away from the heart and syphoned into the oxygenator.

The pump returns the flow to the femoral artery. Before blood reaches the femoral artery it is passed through a heat-exchanger consisting of a series of thin-walled metal tubes set in a water jacket of variable temperature, and through a wire-mesh filter and bubble-trap. The latter is provided with a mercury manometer and warning device to act as a flow-meter and guard against obstruction to flow (Nixon, 1959b).

The oxygenator was designed by Melrose (1953). It is a rotating cylinder set at a slight angle to the horizontal and composed of a number of perspex plates bolted together. As blood travels through the central lumen under the influence of gravity it is filmed over blades which project from the wall, somewhat after the form of an Archimedean helix. A report of its successful use in the U.S.A. has been made by Gerbode, Melrose, Norman, Osborn, Perkins, and Baer (1958), and in England by Cleland, Beard, Bentall, Bishop, Braimbridge, Bromley, Goodwin, Hollman, Kerr, Lloyd-Jones, Melrose, and Telivuo (1958). These authors did not deliberately cool their patients. In Leeds the work of preparation and assembly has been eased by the use of modified plates (Catchpole and Nixon, 1959).
The purpose of this communication is to describe and discuss clinical experience with the Melrose oxygenator in this recent series of 21 consecutive cases, from a total experience of 60 operations in four years.

The age, surface area, and weight of the patients are shown in Table I, together with the duration of perfusion and diagnosis.

TABLE I

CLINICAL SUMMARY OF PRESENT SERIES

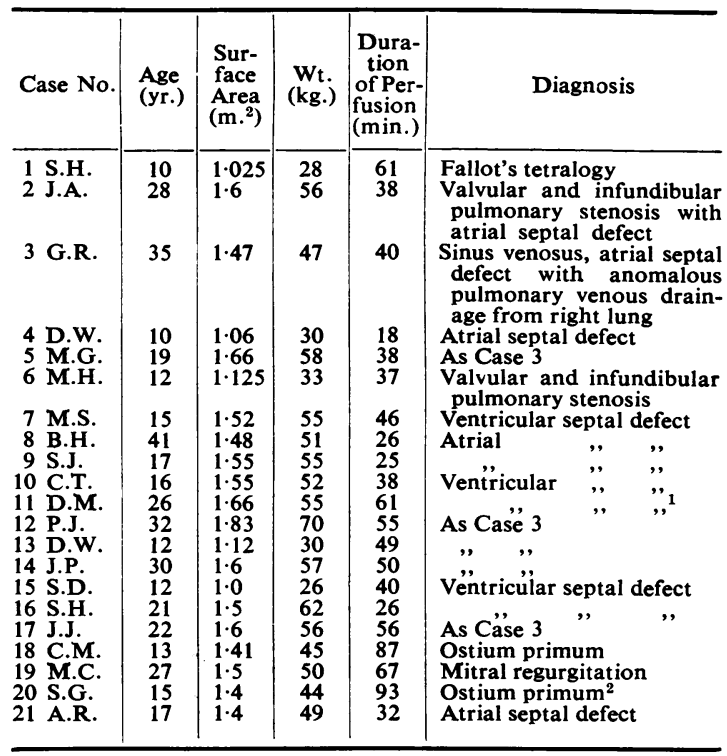

1 Died one month after perfusion from septicaemia.

The flow of blood through the extracorporeal circulation during complete heart and lung by-pass has been varied according to the surface area of the patient and to his temperature at the time of perfusion. For an oesophageal temperature of $37^{\circ} \mathrm{C}$. a flow of 2.4 litres per square metre of body surface per minute was used. In 17 cases a heat- 
exchanger was used to lower body temperature in order that a smaller blood flow would suffice to meet the reduced metabolic requirements of the patient. Table II shows the blood-flow requirement

TABLE II

BLOOD FLOW RATES (AT $37^{\circ}$ C. AND AT REDUCED TEMPERATURE) AND OESOPHAGEAL TEMPERATURE

\begin{tabular}{|c|c|c|c|}
\hline Case No. & $\begin{array}{c}\text { Blood Flow Rate } \\
\text { at } 2 \cdot 4 \text { Litres per } \\
\mathrm{m}^{2} \text { per Minute at } \\
37^{\circ} \text { C. (Litres per } \\
\text { Minute) }\end{array}$ & $\begin{array}{c}\text { Oesophageal } \\
\text { Temperature } \\
\text { Obtained by Use } \\
\text { of Heat } \\
\text { Exchanger ( }\end{array}$ & $\begin{array}{l}\text { Blood Flow Rate } \\
\text { Used at Reduced } \\
\text { Temperature } \\
\text { (Litres per } \\
\text { Minute) }\end{array}$ \\
\hline $\begin{array}{r}1 \\
2 \\
3 \\
4 \\
5 \\
6 \\
7 \\
8 \\
9 \\
10 \\
11 \\
12 \\
13 \\
14 \\
15 \\
16 \\
17 \\
18 \\
19 \\
20 \\
21\end{array}$ & $\begin{array}{l}2.5 \\
3.84 \\
3.54 \\
2.55 \\
4.0 \\
2.75 \\
3.65 \\
3.56 \\
3.72 \\
3.72 \\
4.0 \\
4.4 \\
2.75 \\
3.84 \\
2.4 \\
3.6 \\
3.84 \\
3.4 \\
3.6 \\
3.4 \\
3.4\end{array}$ & $\begin{array}{l}\text { 二 } \\
\bar{Z} \\
\overline{33} \\
33 \\
33 \\
32 \\
31 \\
32 \\
30 \\
33 \\
32 \\
32 \\
32 \\
32 \\
32 \\
28 \\
31 \\
28 \\
33\end{array}$ & 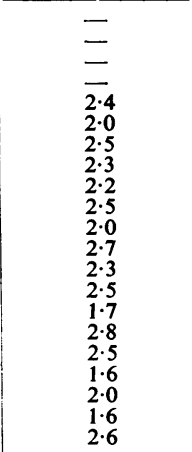 \\
\hline
\end{tabular}

of each patient at $37^{\circ} \mathrm{C}$., the oesophageal temperature obtained by use of the heat-exchanger, and the flow which was considered adequate at the reduced temperature.

The function of an oxygenator is to act as a lung during total heart and lung by-pass. It must add oxygen and remove carbon dioxide without damaging or infecting the blood flowing through it, and without causing the patient metabolic injury. It is convenient to discuss the use of the Melrose oxygenator under a number of headings, namely, the preparation and the oxygenating capacity, the effect on acid-base balance, possible complications, and economy.

\section{Preparation}

Immediately after use the oxygenator is washed through with cold water and dismantled. Each part is wiped to remove fat, steeped in cold water, washed twice in hot soapy water by a technician wearing rubber gloves, rinsed and steeped in cold water, and dried with a soft towel. The perspex plates are inspected, and scratched ones are replaced. After every fifth or sixth perfusion the plates are polished ("perspex" polish No. 2, I.C.I.).

The oxygenator is then assembled in a clean room by a technician wearing rubber gloves. The purpose of the rubber gloves is to prevent deposition on the plates of fingerprint grease which prevents filming, and does not allow the plate to be wetted by antiseptic.
A light coating of "antifoam" is then applied to the end plate and to the pool at each end $(10 \mathrm{ml}$. of a solution containing one tablespoonful of silicone M.S. " antifoam A" in $100 \mathrm{ml}$. of ether applied with a de Vilbiss spray).

Next the oxygenator is filled to overflowing with an aqueous solution containing benzalkonium chloride $1 \%$ and formalin $1 \%$, and sealed. Care is taken to remove all bubbles by gentle shaking.

For use, the oxygenator is taken to the operating theatre and erected upon its stand after the antiseptic solution has been tipped out.

Under aseptic conditions the various tubes that enter are placed in position; and the pump is used to wash at least 40 litres of hot sterile saline solution through the oxygenator. The oxygenator, pump, heat exchanger, filter, and tubing are then primed with 2.5 litres of blood, and the extracorporeal circulation is ready to be joined to the patient. As soon as the oxygenator is primed, a mixture of $97 \%$ oxygen with $3 \%$ carbon dioxide is allowed to flow into it at a rate of 1 to 2 litres per minute.

Care is taken during preparation to ensure that tubing delivering blood to the oxygenator joins it in such a way as to prevent frothing. Care is also taken to ensure that the gas-inflow pipe does not deliver bubbles under the surface of the blood.

Samples of saline used for washing out the oxygenator and samples of blood at the end of perfusion are removeg for bacteriological examination.

\section{Oxygenating CAPacity}

The chief factors affecting oxygenating capacity in clinical practice are the level of blood in the oxygenator, the speed with which the oxygenator is rotated, the rate of blood flow through the instrument, the supply of gas, and the temperature of the corporeal and extracorporeal circulations.

The level of blood in the oxygenator is important, and during perfusion it must be watched constantly. If it is set too high blood will flow through the cylinder in a stream without being adequately filmed for gaseous exchange. Frothing and air 8 emboli may result from its being set too low.

The speed of rotation of the oxygenator has 을 varied between 45 and 80 revolutions per minute. $D$ The slower speed suffices for small blood flows, of the order of 1.5 litres per minute. When the level of $N$ blood is low the need to prevent frothing enforces ? a slow speed.

With larger flows, of say 3.0 litres per minute, స్ట there is a tendency for blood to stream down the centre of the oxygenator. A high speed of rotation 0 is then required to produce sufficient centrifugal force $\frac{D}{\Phi}$ for filming on the walls and blades of the cylinder.

Gas is supplied to the oxygenator in the form 7 of an unheated and unmoistened mixture of $97 \%$ oxygen and $3 \%$ carbon dioxide at a rate of 16 to 
20 litres per minute. The selection of this flow was empirical. Eight litres per minute seemed inadequate, and no benefit was obtained from flows greater than 20 litres per minute.

The effect of hypothermia on the exchange of oxygen in an artificial lung is an interesting study. Preliminary observations from the present method suggest that cooling down to $28^{\circ}$ decreases the metabolic requirements of the body at a greater rate than it impairs the efficiency of the oxygenator.

Hypothermia thus offers a method by which the blood flow requirements of large patients may be brought within the range of a given oxygenator.

During perfusion it is customary to remove samples of blood from the venous and arterial ends of the oxygenator. In Fig. 1 the percentage

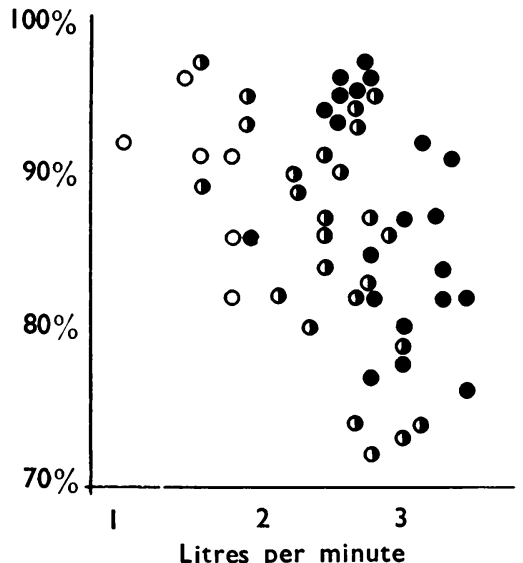

FIG. 1.-The percentage oxygen saturation of samples of arterialized blood leaving the oxygenator related to blood flow through the extracorporeal circulation. The patients' oesophageal temperature at the time of sampling is represented by symbols. $\mathrm{O}=28$ $30^{\circ} \mathrm{C}$; $\boldsymbol{O}=31-33^{\circ} \mathrm{C}$; $\odot=34-36^{\circ} \mathrm{C}$

oxygen saturation of 51 samples of blood leaving the oxygenator during complete heart and lung by-pass in 20 patients is plotted against the rate of blood flow through the extracorporeal circulation. The symbols indicate oesophageal temperature at the time of sampling. It may be seen that oxygen saturation was less than $90 \%$ in half the samples of arterialized blood, and less than $80 \%$ in a fifth. A more practical statement of these observations is that $90 \%$ saturation was guaranteed with a blood flow of 1.5 litres per minute, and $80 \%$ saturation with 2.5 litres per minute, when the oesophageal temperature of the patient was between 28 and $36^{\circ}$ C. Maximum saturation was attempted in every perfusion.

A question of great importance may be asked. Is the perfusion of patients with undersaturated blood harmful, or is it a matter of little consequence?
The answer appears to be that injury is not caused to the patient when the present technique is used. The answer may be different when other anaesthetic agents, gas mixtures, and methods of cooling are employed. The evidence for this view is fourfold. First, the saturation of mixed venous blood has fallen during perfusion to maintain an arteriovenous difference similar to that which existed before perfusion. Secondly, any metabolic acidosis arising during perfusion has been slight and easily corrected; this point will be discussed later. Thirdly, there has been no electro-encephalographic evidence of cerebral disturbance from anoxia during perfusion. Fourthly, in a series of 21 consecutive patients there has been no post-operative evidence of anoxic injury from perfusion.

Perfusion with undersaturated blood may not be ideal, but it must be demonstrated to be harmful before it is condemned out of hand.

\section{ACID-Base Balance}

The $p \mathrm{H}$ of the patient's blood before perfusion is largely dependent upon the technique of the anaesthetist. The $p \mathrm{H}$ of blood that primes the extracorporeal circulation is greatly affected by the method of collection and storage. The $p \mathrm{H}$ at the beginning of perfusion reflects the mixing of blood from these two sources.

The chief determinants of blood $p \mathrm{H}$ during perfusion are the rate of carbon dioxide elimination and the efficiency of tissue oxygenation. Metabolic acidosis is caused by tissue anoxia, respiratory acidosis by carbon dioxide retention. Excessive carbon dioxide loss causes respiratory alkalosis. It follows that $p \mathrm{H}$ changes are an important guide to the efficiency of gaseous exchange in the extracorporeal circulation, just as levels of venous pressure reflect the success with which blood flows and volumes are controlled.

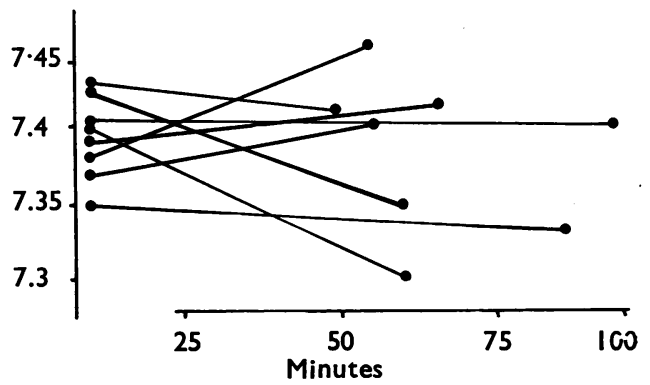

FIG. 2. - The $p H$ changes in the eight patients perfused for 50 minutes or longer. The pairs of dots indicate the $p H$ of blood priming the extracorporeal circulation and the $p H$ at the end of perfusion respectively. The duration of perfusion is indicated by the length of the lines joining the dots. 
In Fig. 2 the $p \mathrm{H}$ of blood priming the extracorporeal circulation just before perfusion is shown joined by a line to the $p \mathrm{H}$ of arterial blood at the end of perfusion. The length of the line indicates the duration of perfusion. For clarity, values are only given for the eight perfusions lasting 50 minutes or more. It may be seen that relatively little alteration occurred. The infusion of 200 to $300 \mathrm{ml}$. of $5 \%$ sodium bicarbonate solution at the end of heart-lung by-pass has readily corrected any tendency to metabolic acidosis and loss of bufferbase.

\section{Possible Complications}

Any patient undergoing perfusion is at risk from blood damage, emboli, and infection.

The clinical manifestations of blood damage are excessive haemolysis and failure to clot. Laboratory and clinical experience suggests that these complications stem from squirting blood through small orifices or from the incorrect dosages of heparin and protamine sulphate. They have not occurred in more than 50 perfusions with the apparatus described.

Plasma haemoglobin measurements were made at the end of perfusion in 19 patients. The value was less than $30 \mathrm{mg} . \%$ in nine and between 31 and $50 \mathrm{mg} . \%$ in eight. Two patients showed levels of 61 and $135 \mathrm{mg} \%$ respectively, attributable to the suction of large bronchial flows from the heart. These levels are considerably lower than those reported by Nixon (1959a), and the improvement is thought to be due to the collection of blood in plastic bags instead of bottles (Snow and Coulson, 1960).

Emboli may consist of gas, fibrin, or of foreign bodies. Examination of the 140 gauge wire mesh filter after operation has not shown fibrin or foreign bodies in the present series. Early in perfusion experience a small amount of fibrin was deposited when blood was not adequately mixed with the heparin-saline solution during collection from the donor.

Gas emboli may arise from frothing in the oxygenator or from perfusion with blood colder than the patient containing an excessive amount of gas. No evidence of gas emboli, arising from the heart-lung machine, has been found in more than 50 clinical perfusions.

Frothing in the Melrose oxygenator does not appear to be a hazard when attention is paid to the siliconing of the pools at the upper and lower ends, when gas is not blown into the cylinder below the surface of the blood, and when the level of blood in the oxygenator is adequate for its speed of rotation.

\section{INFECTION}

Organisms have not been detected in the saline used to wash out the oxygenator before perfusion, or in the blood remaining in the oxygenator after operation. This is regarded as a tribute to the care with which the technician has cleaned and prepared the apparatus. One patient died from staphylococcal septicaemia arising from wound $\vec{\circ}$ infection acquired during convalescence. Phage typing suggested that the infection came from a patient suffering from chronic empyema, and not from the surgical team or its equipment.

It is the current practice to use antibiotic prophyl- $\vec{\sigma}$ axis only when pathogenic organisms are detected $\dot{\omega}$ in the nose or groin of patients before operation.

It is hoped that an autoclavable oxygenator of similar pattern will soon be developed to replace the present perspex model.

\section{ECONOMY}

A technician working alone requires approximately one day for dismantling, cleaning, and assembling the oxygenator. A model made from autoclavable parts would need as much work. It is clear that a disposable artificial lung would offer great advantages.

The Melrose oxygenator alone is primed wit 1.5 litres of blood before use. This is an economica amount. No devices are used to maintain a constant volume in the oxygenator because the maintenance of a constant volume in the patient is considered to be of greater importance.

\section{SummaRY AND CONCLUSIONS}

Clinical experience with the Melrose oxygenator has confirmed that it may be used safely in human perfusion. Gaseous exchange has been effected without complication in a series of 21 consecutive patients, most of whom were of adult size, during heart and lung by-pass lasting for as long as 93 minutes.

Blood flowing at 3.0 litres per minute was sometimes fully oxygenated, but the oxygenator did not consistently saturate flows measuring more than 1.5 litres per minute in patients with oesophageal temperatures ranging between $28^{\circ}$ and $36^{\circ} \mathrm{C}$.

Intravascular cooling with a heat exchanger enabled the oxygen requirements of large patients to be reduced to a level which permitted safe perfusion with the Melrose oxygenator. It also conferred the advantage of low flow which permits longer perfusion without blood damage, because the blood passes less frequently round the extracorporeal circulation in the course of heart and lung by-pass. 
The present oxygenator is made from " perspex" which requires chemical sterilization. Its replacement with an autoclavable model should remove the risk of infection, but will not greatly reduce the labour of preparation for operation. An efficient disposable oxygenator is greatly to be desired.

The original perspex oxygenator was purchased from New Electronic Products Limited, 360 Kennington Road, London, S.E.11. The modified plates from which further oxygenators have been made were obtained from Lusterlite Products Limited, 56 Devon Road, Leeds 2.

The filter and bubble-trap and the heat exchanger were manufactured by New Electronic Products Limited.

Blood percentage oxygen saturation was measured spectrophotometrically using a Kipp " haemoreflector." and "stanco" cuvette oximeter. Both instruments were calibrated with every use against the Van Slyke manometric method.

To measure whole blood $p \mathrm{H}$ the Stadie electrode system and Cambridge bench meter were used. All measurements were made at a temperature of $37.5^{\circ} \mathrm{C}$., and corrected to the patient's temperature according to the formula $p \mathrm{H}$ patient $=p \mathrm{H}\left(37.5^{\circ} \mathrm{C}\right.$.) -0.0149 (temperature of patient-37.5) (Rosenthal, 1948).

Plasma haemoglobin levels were measured by the method of Fielding and Langley (1958) on blood samples drawn into oiled heparinized syringes and centrifuged at 3,000 r.p.m. for 20 minutes.

Surface area was calculated from a nomogram based on the Du Bois formula.

Blood used for priming the extracorporeal circulation contained $20 \mathrm{mg}$. of heparin sulphate in each pint.
Heparin sulphate was administered to the patient in a dose of $2.5 \mathrm{mg}$. per $\mathrm{kg}$. of body weight.

Protamine sulphate was given at the end of perfusion, and, if necessary, after four to six hours, to neutralize the heparin. The total dose of protamine given to each patient was of the order of 2.5 to $3 \mathrm{mg}$. per $\mathrm{kg}$. body weight.

We wish to thank Dr. A. Ambrey-Smith and Mr. A. Coulson for their unfailing and generous co-operation in collecting and preparing blood for use at operation.

Dr. D. G. Melrose, and Mr. Z. F. Kellerman of New Electronic Products Limited, have given generously of their time to help us with the problems of extracorporeal circulation.

This work has been made possible by the generosity of the Trustees of the Nuffield Foundation and the Board of Governors of the United Leeds Hospitals.

For support and encouragement we are indebted to Mr. G. H. Wooler, who has been responsible for the development of open-heart surgery in this centre.

\section{REFERENCES}

Catchpole, L. A., and Nixon, P. C. F. (1959). Lancet, $2,329$.

Cleland, W. P., Beard, A. J. W., Bentall, H. H., Bishop, M. B., Braimbridge, M. V., Bromley, L. L., Goodwin, J. F., Hollman, A. Kerr, W. F., Lloyd-Jones, E.' B., Melrose, D. G., and Telivuo, L. J. (1958). Brit.med.J., 2, 1369.

Gerbode, F., Melrose, D. G., Norman, A., Osborn, J. J., Perkins, H. A., and Baer, D. M. (1958). Lancet, $2,284$.

Fielding, H. E., and Langley, P. E. (1958). Amer. J. clin. Path., 30, 528.

Melrose, D. G. (1953). Brit. med. J., 2, 57.

Nixon, P. G. F. (1959a). Lancet, 1, 1074.

(1959b). Ibid., 2, 830.

Rosenthal, T. B. (1948). J. biol. Chem., 173, 25.

Snow, H. M., and Coulson, A. (1960). Lancet, 2, 154. 